\title{
OS CIRCUITOS DA ECONOMIA URBANA NA FEIRA LIVRE DO MERCADO CENTRAL DE CEARÁ-MIRIM - RN
}

\author{
R. S. MARANHÃO e T. A N. QUEIROZ* \\ Instituto Federal de Educação, Ciência e Tecnologia do Rio Grande do Norte \\ thiago.augusto@ifrn.edu.br*
}

Artigo submetido em junho/2016e aceito em junho/2016

DOI: 10.15628/geoconexoes.2016.4722

\section{RESUMO}

O atual período técnico-científico-informacional é caracterizado pela existência de elementos do circuito superior da economia urbana. Contraditoriamente, neste período há objetos geográficos do circuito inferior, tais como, os mercados públicos e as feiras livres. Este artigo tem como objetivo mostrar a importância cultural e econômica da feira livre do Mercado Central de CearáMirim e os conflitos políticos que a envolvem. Para tal fim, utilizamos como procedimentos metodológicos, pesquisa bibliográfica, entrevistas, observações e registro fotográficos. Os resultados mostraram a predominância de elementos do circuito inferior da economia urbana na feira livre, algumas características do circuito superior, diversos fluxos locais, regionais e nacionais de pessoas e mercadorias, além de conflitos entre feirantes, consumidores e Estado que envolve a desorganização, a insalubridade e a insegurança da feira livre.

PALAVRAS-CHAVE: Circuitos da Economia Urbana. Feira Livre. Ceará-Mirim.

\section{THE CIRCUITS OF URBAN ECONOMY IN THE PERIODIC MARKET OF CEARÁ-MIRIM, RN, BRAZIL}

\begin{abstract}
The current technical-scientific-informational period is characterized by the existence of elements of the upper circuit of the urban economy. Paradoxically, in this period there are geographic objects of the lower circuit, such as markets and periodic markets. This article aims to show the cultural and economic importance of the periodic market of Ceará-Mirim and the political conflicts that involve. To this end, we used as methodological
\end{abstract}

procedures, literature, interviews, observations and photographic record. The results showed the predominance of lower circuit elements of the urban economy in the periodic market, some features of the upper circuit, several local, regional and national flows of people and commodities, as well as conflicts between merchants, consumers and State involving the disruption, the unhealthiness and insecurity of periodic market.

KEYWORDS: Circuits of the Urban Economy. Periodic Market. Ceará-Mirim. 


\section{INTRODUÇÃO}

As feiras livres brasileiras originaram-se nas cidades europeias da Idade Média. Este costume de se encontrar periodicamente para a realização de trocas, compra e venda, de mercadorias foi trazido pelos colonizadores portugueses para o Brasil. Esse costume desenvolveuse inicialmente no Nordeste do Brasil, especialmente no Agreste, nas cidades que se tornaram ponto de encontro entre o Sertão - produtor de gado - e a Zona da Mata - mercado consumidor. Essas feiras livres eram realizadas juntamente com as conhecidas feiras de gado, principalmente, em Feira de Santana-BA, Arapiraca-AL, Caruaru-PE e Campina Grande-PB. Posteriormente, esse costume foi sendo difundido por todo o Brasil, juntamente com a migração de nordestinos para outras regiões. Atualmente, as feiras livres são importantes nas metrópoles brasileiras também, por exemplo, a feira de São Cristóvão no Rio de Janeiro, a feira da Madrugada em São Paulo e a feira do Mineirinho em Belo Horizonte.

O período atual que vivenciamos é o período técnico-científico-informacional que produz um meio geográfico dotado de técnica, ciência e informação. Esse período é caracterizado pelo avanço de objetos geográficos modernos, lugares de consumo e de consumismo, como os shoppings centers, supermercados e lojas de departamento, que formam um circuito superior da economia urbana. Esse circuito econômico é superior em termos de organização produtiva, tecnologia e capital utilizados. Também é superior em relação a um circuito inferior, formado por objetos geográficos tradicionais, espaços de consumo originados em um período pretérito, por exemplo, os mercados públicos e as feiras livres. Assim, a economia urbana é formada por um circuito superior moderno e, contraditoriamente, um circuito inferior tradicional que resiste, persiste e sobrevive em meio aos conflitos ideológicos do atual período de globalização.

O município de Ceará-Mirim é formado por duas feiras livres. Porém, destaca-se a feira mais antiga que já vem sendo realizada, provavelmente, desde o século XIX, que é a feira livre do Mercado Central. Essa feira inicialmente era realizada todos os sábados e domingos e atualmente apenas aos sábados. Portanto, mesmo diante do avanço dos elementos do circuito superior da economia urbana, como as redes de supermercados em Ceará-Mirim e a modernização da vida urbana e metropolitana, e mesmo este município sendo parte da Região Metropolitana de Natal, capital do estado federado do Rio Grande do Norte, a sua feira livre torna-se importante para a cultura e a economia local e regional. Daí nos questionamos: por quê a feira livre do Mercado Central de Ceará-Mirim, elemento do circuito inferior da economia urbana, continua a existir mesmo com o avanço do circuito superior e da vida moderna na cidade?

Nesse contexto, este artigo tem como objetivo mostrar a importância cultural, econômica da feira livre de Ceará-Mirim e os conflitos políticos que a envolvem. Para tal fim, buscaremos contextualizá-la historicamente como um elemento da cultura local e regional, apresentaremos os diversos fluxos de pessoas (feirantes e consumidores) e de mercadorias que se encontram semanalmente neste lugar de trocas materiais e simbólicas, bem como, demonstraremos os conflitos políticos e ideológicos em torno dessa feira. Como procedimentos fizemos uma pesquisa bibliográfica sobre a história do município e de sua feira livre, entrevistamos feirantes, consumidores e um representante da prefeitura para saber sobre os fluxos de pessoas e mercadorias e os conflitos na feira livre, assim como fizemos observações e registros fotográficos de alguns aspectos mais expressivos e importantes para o trabalho. 
Este artigo está subdivido em três partes. Na primeira secção discutiremos sobre os circuitos da economia urbana, como eles se constituem, seus aspectos no atual período técnicocientífico-informacional, e suas relações com os lugares, territórios e regiões. Na segunda parte abordaremos a feira livre do Mercado Central de Ceará-Mirim, focando na história da feira livre contextualizada na história do município. Por fim, na última secção, mostraremos como as relações dos circuitos da economia na feira livre do Mercado Central de Ceará-Mirim, destacando as redes que são construídas, os territórios que são disputados e os simbolismos do lugar.

\section{OS CIRCUITOS DA ECONOMIA URBANA}

A teoria dos circuitos da economia urbana foi criada pelo geógrafo brasileiro Milton Santo na década de 1970 e publicada em seu livro O espaço dividido no ano de 1979. Essa teoria foi pensada inicialmente para os países subdesenvolvidos (SANTOS, 1979). Porém, devido aos novos fatos empíricos que transcorreram nas décadas seguintes, essa concepção teórica foi ampliada para todos os países do mundo (SANTOS, 1996).

A economia urbana se divide em dois circuitos ou dois sistemas urbanos. O primeiro é o circuito superior, o circuito moderno, que utiliza avançadas tecnologias e muitos capitais. Esse circuito é composto pelas indústrias, pelos transportes modernos, pelos comércios modernos (shoppings centers, supermercados, lojas de departamento) e pelos serviços de média e alta complexidade. O segundo, o circuito inferior, é o circuito não moderno, o circuito tradicional, que não utiliza tecnologias ou utiliza tecnologias residuais e poucos capitais. Esse circuito é formado pelas produções artesanais, pelos transportes que utilizam tração animal, pelos serviços de baixa complexidade e pelos comércios tradicionais como os mercados públicos, e os mercados periódicos, mais conhecidos no Brasil por feiras livres (SANTOS, 1979).

Dentro da rede urbana, o circuito superior e o circuito inferior é maior nos centros com maior população e com maior complexidade funcional, como nas megacidades, megalópoles, metrópoles e cidades grandes. Porém, nas cidades locais e nas cidades pequenas, ou seja, nas cidades com menor população e com menor complexidade funcional, o circuito inferior consegue ter um maior poder de atração regional de fluxos de pessoas e mercadorias que o circuito inferior das cidades maiores. Assim, em dias de mercados periódicos, de feiras livres, aumenta-se a escala da dinâmica socioespacial das cidades menores (CORRÊA, 1988).

Os circuitos da economia urbana se contrapõem, se justapõem e se sobrepõem nos lugares, nas cidades. Os lugares são esses pontos no espaço onde ocorre a dialética entre as verticalidades e as horizontalidades, entre o circuito superior e o circuito inferior, entre as solidariedades organizacionais e as solidariedades orgânicas e entre as racionalidades hegemônicas e as contra racionalidades (SANTOS, 1996). Assim, as feiras livres, em especial a feira de Ceará-Mirim, são lugares onde ocorre essa dialética.

Essa dialética dos lugares entre o circuito superior e o circuito inferior torna-se mais complexa com o advento do período e meio técnico-científico-informacional, a expressão geográfica da globalização (SANTOS, 1996). Essa globalização se caracteriza por três unicidades: a unicidade da técnica, o sistema técnico atual que tende a ser único; a unicidade da informação, a cognoscibilidade do planeta como um todo e a informação em tempo real; e a unicidade do dinheiro, o capital que é o motor-único do atual período (SANTOS, 1996; 2000). 
Essa globalização é ao mesmo tempo: uma fábula, a globalização fabulosa transmitida pelos meios de comunicação e de informação; e uma perversidade, a globalização perversa da realidade dos pobres e excluídos (SANTOS, 2000). Essas duas primeiras formas de globalização são ditadas pelo circuito superior da economia urbana, por meio das relações de verticalidade, das solidariedades organizacionais e das racionalidades e racionalizações.

Porém, a globalização também é uma possibilidade, a globalização possível (SANTOS, 2000). Essa globalização possível está nos interstícios do circuito inferior, como as relações de horizontalidade, as solidariedades orgânicas de proximidade e vizinhança, as contra racionalidades. Todos esses aspectos podem ser encontrados nas feiras livres como foi constatado por Santos (2012) e por Queiroz \& Azevedo (2013).

As feiras livres, enquanto lugares da globalização como possibilidade, estão inseridas nesses conflitos políticos e ideológicos, respectivamente, com o Estado e com o circuito superior (MASCARENHAS, 1992), transformando-se assim em territórios, espaços definidos e delimitados pelas relações de poder (SOUZA, 2013). Também, alguns desses aspectos são encontrados na feira livre de Ceará-Mirim, apesar da falta de organização política dos feirantes na luta contra os ditames do Estado e do circuito superior.

As feiras livres também são compostas por redes materiais (econômicas e técnicas) e por redes sociais (Simbólicas) que se organizam em diversas escalas desde a local até a global (SOUZA, 2013). No caso da feira livre de Ceará-Mirim essas redes materiais e sociais fazem com que a ela participe simultaneamente das escalas locais, regionais e nacionais.

Tais redes, também fortalecem o aspecto regional da feira livre, que forma uma região funcional da cidade de Ceará-Mirim, para além do aspecto político administrativo (Região Metropolitana de Natal, Mesorregião do Leste Potiguar, Microrregião de Macaíba), sendo uma região simultaneamente funcional (da economia e dos fluxos de pessoas e mercadorias) e simbólica (da história e da cultura regional do Nordeste) (SOZUZA, 2013).

\section{A FEIRA LIVRE DO MERCADO CENTRAL DE CEARÁ-MIRIM/RN}

O município de Ceará-Mirim situa-se na Mesorregião do Leste Potiguar e na Microrregião de Macaíba, integrando também a Região Metropolitana de Natal juntamente com Natal, Parnamirim, Macaíba, São Gonçalo do Amarante, Extremoz, São José do Mipibu, Nísia Floresta, Monte Alegre, Vera Cruz, Maxaranguape, lelmo Marinho, Arês e Goianinha. Limita-se ao Norte com o município de Maxaranguape, ao Sul com lelmo Marinho, ao Leste com Extremoz e Oceano Atlântico e ao Oeste com Taipu. Está distante da capital potiguar cerca de $28 \mathrm{~km}$, apresentando como vias de acesso a BR-406 (trecho São Gonçalo do Amarante-Ceará Mirim), e a RN-064 (trecho lelmo Marinho- Barra de Maxaranguape).

O povoamento do município iniciou-se com os índios da tribo Potiguares às margens do rio Ceará-Mirim, que significa pequeno rio onde canta o papagaio. Posteriormente, essas margens foram colonizadas pelos portugueses. No final do século XIX, o vale do rio já era próspero na produção de cana-de-açúcar e havia o uso do trabalho escravo de negros africanos. Em 1855, o povoado de Ceará-Mirim, até aquele momento era denominado de Boca da Mata, tornou-se a sede do distrito de Extremoz. Em 1882, emancipou-se para a condição de cidade. Em 1937, é 
constituído o município de Ceará-Mirim. O gentílico Ceará-mirinense é utilizado para quem é natural de Ceará-Mirim (IBGE, 2016).

O município possui uma unidade territorial de $724,77 \mathrm{~km}^{2}$ e população de 68.141 habitantes de acordo com os dados do Censo Demográfico de 2010 do Instituto Brasileiro de Geografia e Estatística (IBGE). Sua economia está atrelada, principalmente, aos comércios e serviços (54\% do PIB de R\$259.258.000,00), seguido da agropecuária (36\% do PIB) e da indústria (10\% do PIB) (IBGE, 2016). As atividades de comércio e de serviços abarcam 92\% dos negócios formais e 99\% dos negócios informais do município de Ceará-Mirim (SEBRAE, 2016). Esse setor terciário é formado pelo comércio das lojas, supermercados e mercado do centro da cidade e também pela feira livre do Mercado Central que é realizada aos sábados (Foto 01).

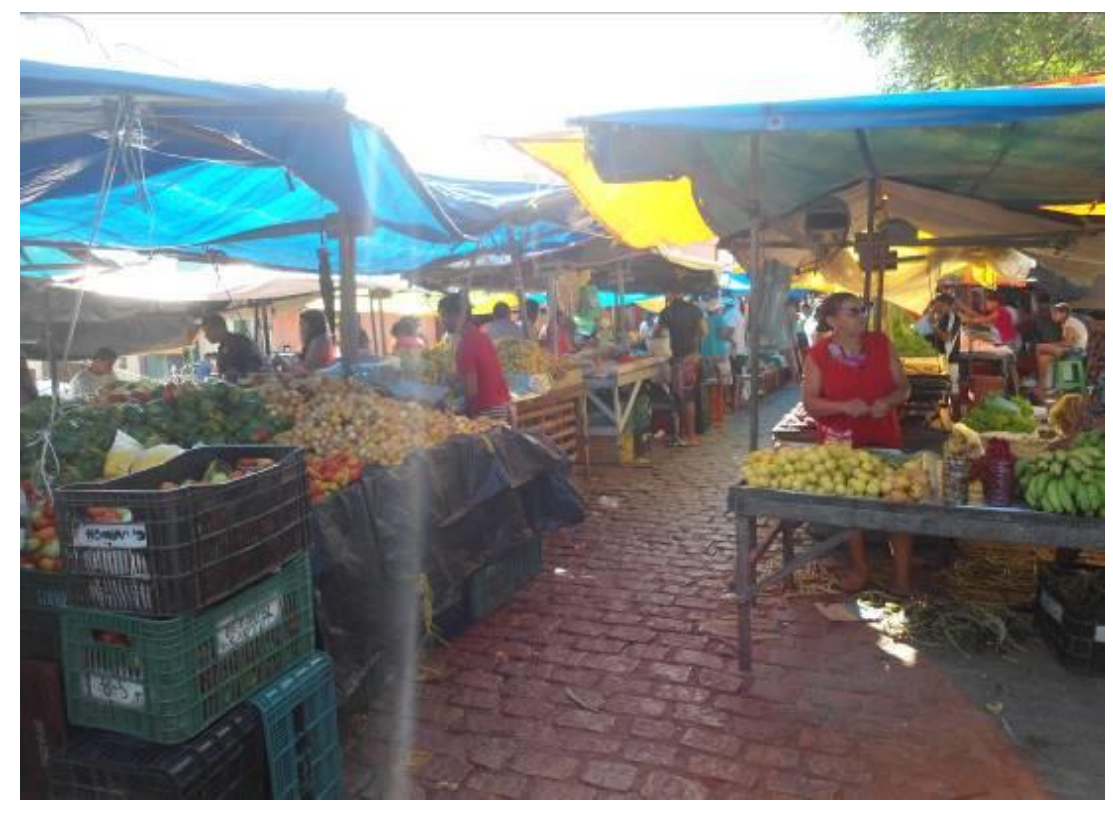

Foto 01 - Feira livre do Mercado Central de Ceará-Mirim.

Foto: Renata de Sousa Maranhão, Agosto 2015.

De acordo com o representante da Secretaria Municipal de Agricultura, que é o órgão responsável pela organização e administração da feira livre no município, a feira livre de CearáMirim tem uma importância cultural e histórica para a cidade, que remonta à época dos engenhos, ao processo de produção do território do Rio Grande do Norte, quando a cana de açúcar foi a atividade econômica que fixou a população na Zona da Mata do estado

Rapaz... a feira de Ceará-Mirim é uma feira tradicional, né?!, inclusive vem gente da região fazer compra aqui. Então assim, ela tem uma importância até histórica, eu poderia dizer, né?! Que é da época dos engenhos, daquela coisa toda. (Entrevista realizada no dia 11 de Abril de 2016 com o representante da Secretaria Municipal de Agricultura).

A feira livre do Mercado Central de Ceará-Mirim ocorre nas ruas: Praça Onofre José Soares, em frente ao Mercado Central (Foto 02); Pacheco Dantas; Nove de Julho; e José Olímpio Alves Pereira. A praça do mercado é o centro comercial da cidade. Ao seu entorno encontram-se as lojas de material para construção, supermercados, eletrodomésticos, sapataria entre outras atividades 
de serviços e comércio. Todo esse conjunto de comércio e serviços torna-se mais dinâmico nos dias de feira.

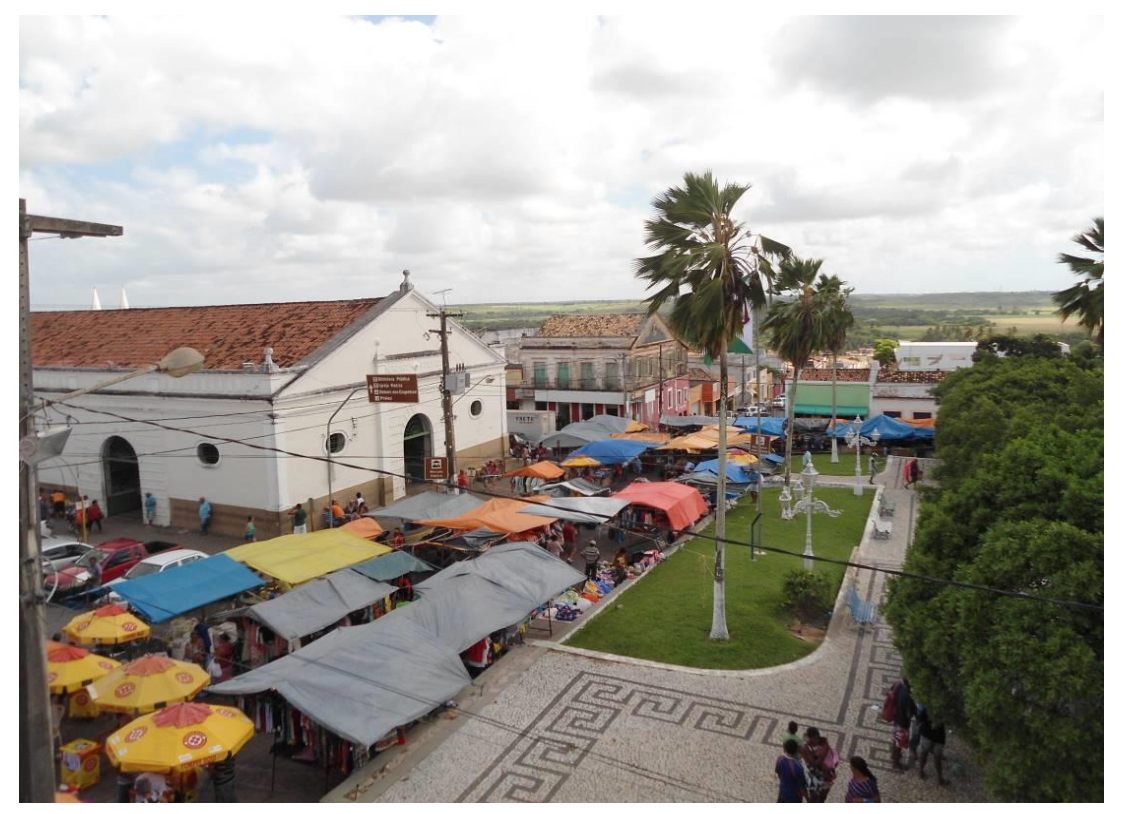

Foto 02 - Largo do Mercado Central e sua feira livre.

Foto: Renata de Sousa Maranhão, Agosto 2015.

Não existe uma data certa para a criação da feira livre de Ceará-Mirim. A feira já existia na época da vila de Ceará-Mirim e essa feira livre foi crescendo com a emancipação da cidade, e posteriormente com a construção da Igreja Matriz em 1900. A feira de Ceará-Mirim era realizada tradicionalmente todos os sábados e domingos nos arredores da Igreja. Até que, segundo o autor, devido a uma cheia do rio Ceará-Mirim, evento não datado, a feira foi inundada. Posteriormente, foi transferida para o local atual nos arredores e proximidades do Mercado Central (MELO, 2011).

Durante a década de 1960 foi feito um teste para que a feira fosse realizada apenas aos sábados. Porém não deu certo, pois somente no sábado à noite os funcionários da usina de canade-açúcar recebiam seus pagamentos, daí a feira voltou a ser realizada aos domingos. Porém, a realização da feira aos domingos fazia com que os comerciantes trabalhassem também ao longo do final de semana, o que tornava o trabalho mais oneroso e cansativo. Assim, desde 1987, a feira é realizada apenas aos sábados devido a um decreto municipal (MARANHÃO, 2012).

Sabendo da importância histórica e cultural da feira livre de Ceará-Mirim, partiremos para a análise política e econômica que envolve esta feira, destacando os circuitos da economia urbana que produzem esse lugar, as redes e suas escalas e os conflitos políticos e territoriais que envolvem essa feira livre.

\section{OS CIRCUITOS DA ECONOMIA URBANA NA FEIRA LIVRE DO MERCADO CENTRAL DE CEARÁ-MIRIM/RN}

A feira livre de Ceará-Mirim é uma expressão do circuito inferior da economia urbana na medida em que não há necessidade de grandes capitais para participar dela, basta ter no mínimo uma lona ou um pedaço de papelão para expor os produtos no chão, como notamos na Foto 03. Essas mercadorias podem ser produzidas pelo próprio feirante como é o caso dos artesanatos e das hortaliças. Constatamos em trabalho de campo que a feira livre se caracteriza pelo trabalho 
intensivo, pela grande quantidade de pessoas que participam da montagem e desmontagem das bancas, da organização e desorganização dos produtos e da venda das mercadorias.

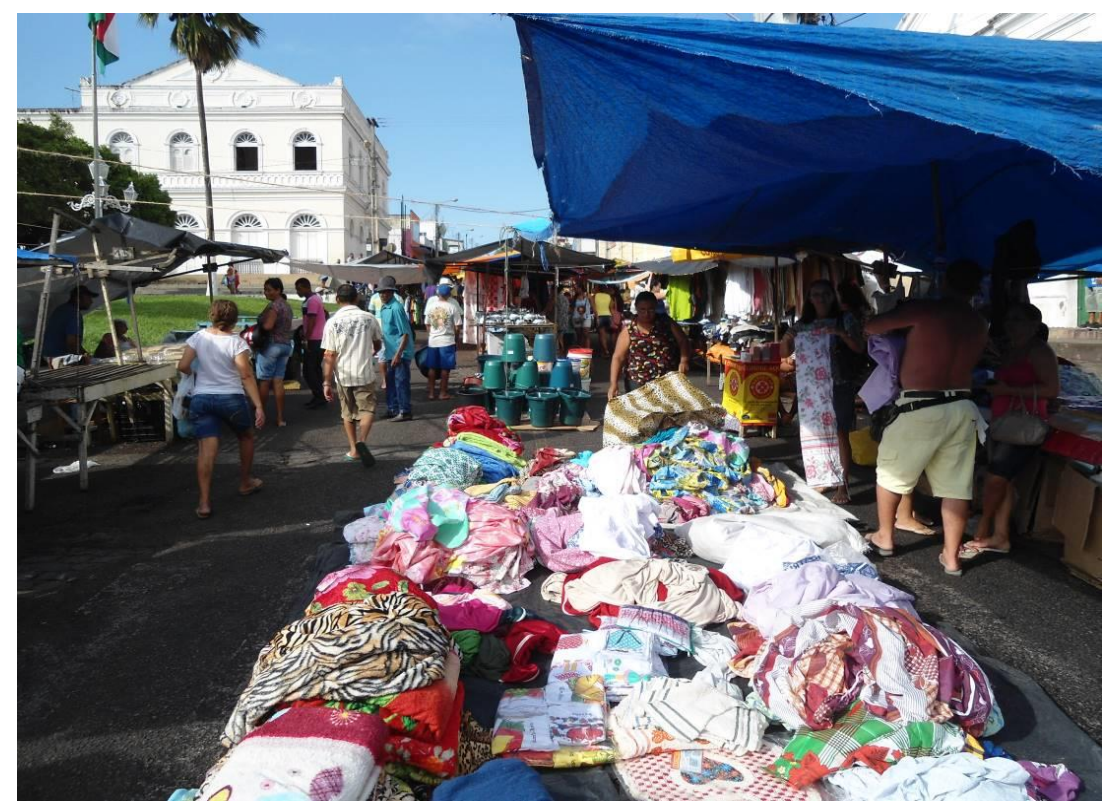

Foto 03 - Estrutura das instalações.

Foto: Renata de Sousa Maranhão, Agosto 2015.

A organização da feira livre de Ceará-Mirim também expressa o circuito inferior da economia urbana, pois, não há uma divisão lógica entre as secções (frutas, legumes, verduras, alimentos não perecíveis, carnes, aves, peixes, roupas, acessórios) como ocorre em supermercados (empresas do circuito superior da economia). Observamos, no trabalho de campo, que não há uma lógica de organização quando ficam lado a lado bancas de venda de aves e de roupas, como podemos observar na Foto 04.

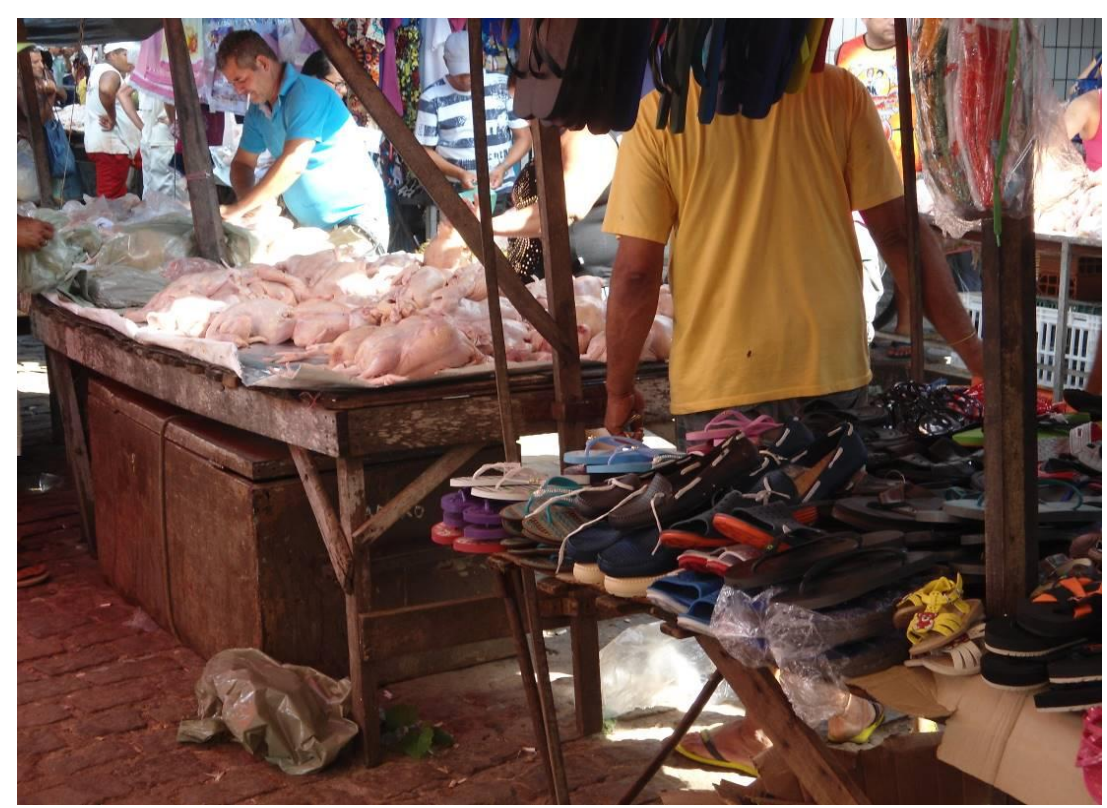

Foto 04 - Organização das bancas.

Foto: Renata de Sousa Maranhão, Agosto 2015. 
Essa estrutura da organização, da infraestrutura (do meio ambiente) da feira livre é foco de diversos conflitos políticos e territoriais, que envolvem os agentes do espaço como as pessoas (os feirantes e consumidores) e as instituições (o Estado e seus órgãos públicos), conforme aponta a entrevista com o representante da Prefeitura Municipal de Ceará-Mirim

\begin{abstract}
Os problemas são diversos, por exemplo, a comercialização do frango in natura, né?! É um problema, precisa ser resolvido, mas por outro lado tem a questão cultural das pessoas, né? É claro que a vigilância sanitária, as normas, elas precisam ser atendidas, mas assim, devido ao pouco conhecimento das pessoas, muitas delas querem realmente comprar aquele tipo de frango, que é o frango abatido, que eles chamam de frango abatido na hora, que na verdade ele não é abatido na hora, né?! Abatido de madrugada, num sei que horas e tal. Mas assim, existe o problema do frango, existe o problema da padronização das bancas, existe o problema da obstrução das ruas. Existe uma série de problemas. Aquela coisa, problema existe em todo canto e que não são problemas recentes, eles ocorrem desde que existe a feira. Na verdade não são só os frangos, mas são os produtos de origem animal, que precisam seguir um protocolo de abate, de refrigeração, de embalagem, de validade...de tudo, né?! (Entrevista realizada no dia 11 de Abril de 2016 com o representante da Secretaria Municipal de Agricultura).
\end{abstract}

Constatamos também na entrevista que a Prefeitura também não dá total suporte aos feirantes, cooperando apenas na limpeza da feira livre. Não há auxílio quanto à água, a energia elétrica, e a segurança para este lugar da cidade. Todavia, existe um projeto de organização da feira livre, que não foi posto em prática devido à falta de recursos. Também existe a ideia de construção de um camelódromo. Porém todos esses projetos foram idealizados sem a participação política dos feirantes, ou seja, essa organização da feira e de um possível camelódromo não passa pela avaliação dos próprios usuários do espaço, no caso os feirantes.

A luta dos feirantes por uma feira livre salubre, segura e organizada torna-se mais difícil devido à falta de uma associação ou cooperativa dos feirantes da feira livre de Ceará-Mirim. Os feirantes foram reunidos e treinados pelo Serviço Brasileiro de Apoio às Micro e Pequenas Empresas do Rio Grande do Norte (SEBRAE-RN), porém, não houve êxito devido à falta de conscientização de classe por parte dos feirantes e o desinteresse em formar associações ou cooperativas.

Outra expressividade do circuito inferior da economia urbana na feira livre de Ceará-Mirim é a sua capacidade de gerar emprego, não assalariado e sem carteira de trabalho assinada, os denominados empregos informais. Também há a importância do trabalho familiar que ajuda os feirantes. Dos dez feirantes que foram entrevistados, quatro deles responderam que recebem ajuda de familiares nas bancas e os outros seis trabalham e comercializam sozinhos. Sete dos dez feirantes afirmaram que sobrevivem da renda gerada na feira, pois só trabalham nesta atividade. Apenas três utilizam outra forma de gerar dinheiro e complementam sua renda com a feira.

Como não há uma necessidade de grandes capitais para iniciar a comercialização na feira, esta torna-se o lugar dos desempregados que passam a ser autônomos, assim a feira livre vem crescendo no número de feirantes no últimos anos. O representante da Secretaria Municipal de Agricultura enfatizou na entrevista a importância da feira em empregar as pessoas que foram 
demitidas de empresas devido à crise política e econômica que estamos vivenciando no Brasil desde 2013:

Só que os feirantes é muito dinâmico, alguns ficam direto, outros estão vindo devido a crise, pela necessidade, invés da feira estar diminuindo, ela está aumentando devido a necessidade. (Entrevista realizada no dia 11 de Abril de 2016 com o representante da Secretaria Municipal de Agricultura).

De acordo com os relatos da atividade de campo, alguns dos feirantes, por exemplo, trabalhavam como cortadores de cana-de-açúcar para a usina de açúcar. Com a falência e o fechamento da usina, e por não terem formação adequada para assumir outros campos de emprego, esses trabalhadores acabaram montando suas bancas na feira livre. Contraditoriamente, os feirantes apontaram nas entrevistas que o fechamento da usina e o desemprego gerado provocou uma diminuição nas vendas, pois diminuiu o dinheiro circulante no município.

Os trabalhos de campo também mostraram que outra expressividade do circuito inferior da economia urbana na feira livre de Ceará-Mirim são os estoques reduzidos em relação às empresas do circuito superior. Esses estoques são guardados em caixas que ficam em baixo das bancas, como podemos observar na Foto 05.

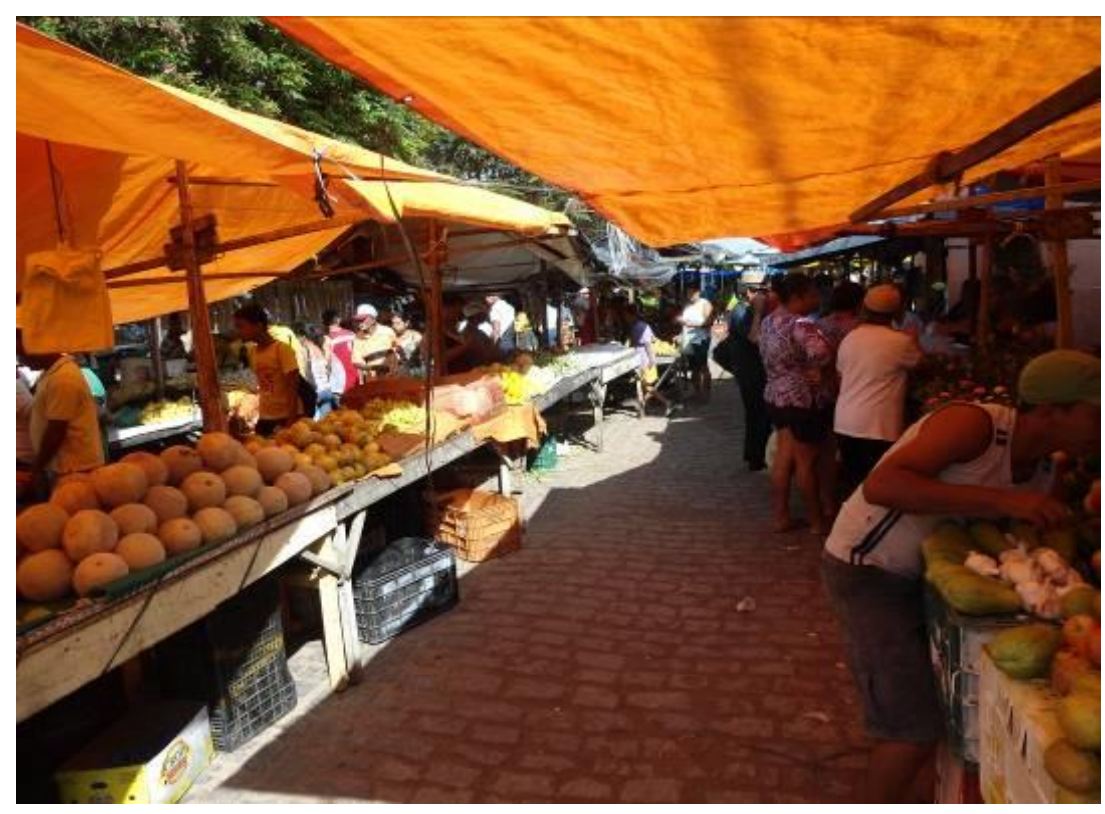

Foto 05 - Estoque de mercadorias.

Foto: Renata de Sousa Maranhão, Agosto 2015.

Os preços, geralmente, menores em relação aos encontrados nos supermercados, devido à barganha e à pechincha; as relações diretas e personalizadas entre os vendedores e a clientela, ou seja, o contato direto entre vendedor e consumidor mostrado na Foto 06; o lucro reduzido em relação ao pequeno volume de mercadorias vendidas e aos custos fixos existentes para os feirantes, que geralmente paga o aluguel da banca, o frete ou combustível pelo transporte da mercadoria, e o seu próprio deslocamento de casa para a feira livre; são características da feira livre de Ceará-Mirim que também são expressões do circuito inferior da economia urbana. 


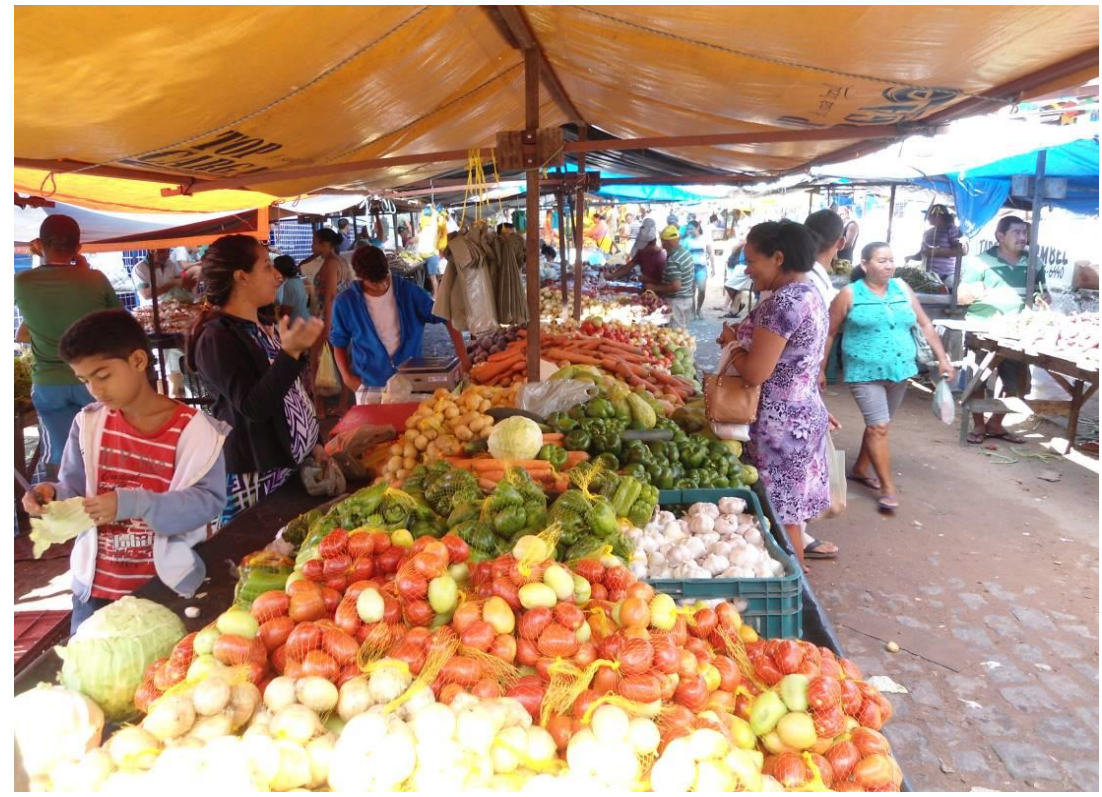

Foto 06 - Contato direto entre consumidor e feirante.

Foto: Renata de Sousa Maranhão, Agosto 2015.

As entrevistas com os consumidores apontaram que eles gostam do contato direto com o feirante e das negociações dos preços da mercadoria. Laços de amizade entre feirantes e consumidores também são criados, pois, um dos dez consumidores entrevistados indicou que compra sempre no mesmo vendedor, por ele lhe tratar bem e pela amizade construída ao longo de anos. Todas essas características relatadas pelos frequentadores da feira, expressam as relações de proximidade e vizinhança do circuito inferior da economia urbana.

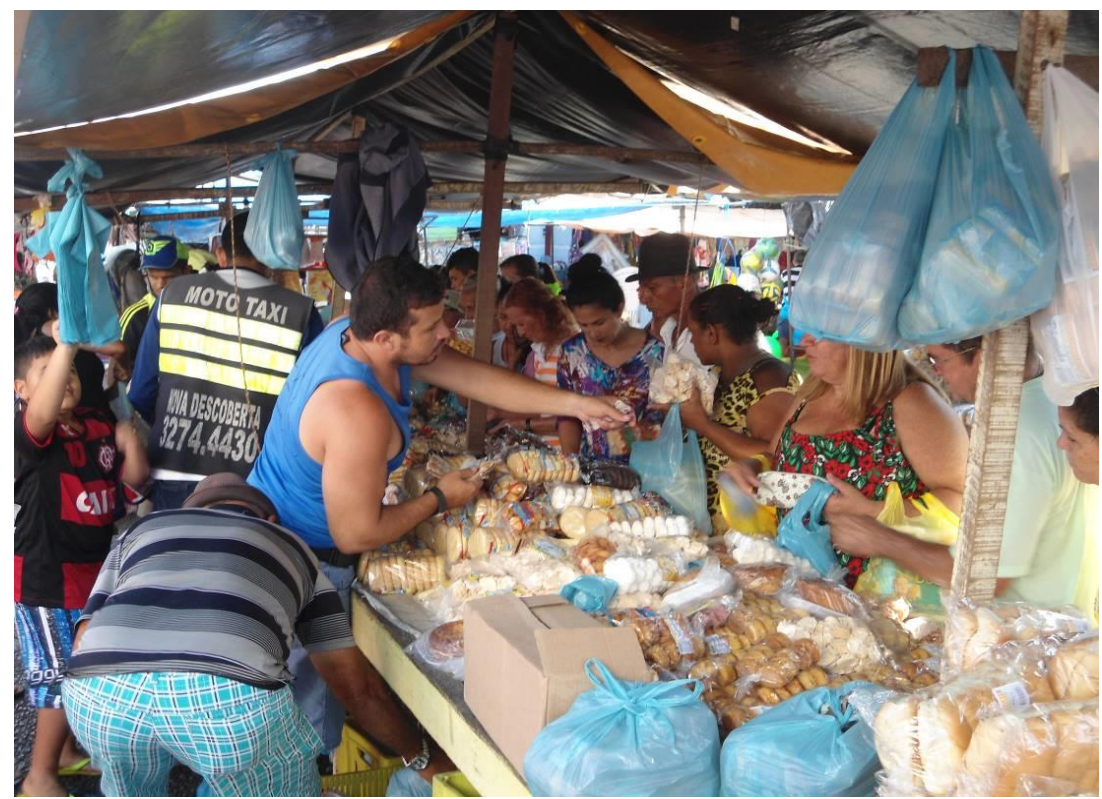

Foto 07 - Elementos do circuito superior na Feira Livre.

Foto: Renata de Sousa Maranhão, Agosto 2015.

O circuito inferior da economia urbana não está isolado do circuito superior, o circuito moderno. Ao contrário, há uma imbricação entre os dois circuitos, uma mistura, uma simbiose. Os trabalhos de Queiroz (2011) e Queiroz \& Azevedo $(2012$; 2013) já demonstravam os usos das feiras livres por empresas do circuito superior, como meio e estratégia de capitalizar seus produtos em 
outras camadas sociais. Portanto, na feira livre de Ceará-Mirim também é possível encontrar elementos do circuito superior da economia urbana como podemos notar a venda de grandes marcas nacionais e internacionais, além de produtos industrializados como observamos na Foto 07.

De dez feirantes que foram entrevistados, nove afirmaram residir na zona urbana do município de Ceará-Mirim, e o outro feirante reside na cidade de Natal, como podemos observar no Quadro 01. Pode-se auferir que a feira livre gera emprego principalmente para os residentes no próprio município.

Quadro 01 - Feirantes: Município em que residem.

\begin{tabular}{|c|c|c|}
\hline Feirantes & Ceará-Mirim & Outro município \\
\hline 01 & $x$ & ------------ \\
\hline 02 & $x$ & ------------- \\
\hline 03 & $x$ & ------------ \\
\hline 04 & $x$ & ------------ \\
\hline 05 & ------------ & Natal \\
\hline 06 & $x$ & ----------- \\
\hline 07 & $x$ & ------------ \\
\hline 08 & $x$ & ------------ \\
\hline 09 & $x$ & ------------ \\
\hline 10 & $x$ & ----------- \\
\hline
\end{tabular}

Fonte: Pesquisa de campo, Agosto, 2015.

Além das redes formadas entre o local de moradia de feirantes e a feira livre, há também a rede formada pelos feirantes que participam de outras feiras livres nos municípios próximos à Ceará-Mirim (feira de Taipu, feira de Poço Branco, feira de Touros, feira de São Miguel do Gostoso, feira de Zumbi em Rio do Fogo) ou em distritos do próprio município (feira de Maracajaú), conforme foi relatado nas entrevistas.

A feira livre de Ceará-Mirim é um importante nó na rede de fluxos de pessoas, como também, é um ponto de encontro na rede de mercadorias. As roupas e confeç̧ões são fabricadas, de acordo com os relatos de campo, na Paraíba (Campina Grande), no Ceará (Fortaleza) e em Pernambuco (Caruaru, Santa Cruz do Capibaribe, Toritama). Em relação aos alimentos, há os produzidos no próprio município de Ceará-Mirim e de municípios vizinhos, que são vendidos na feira pelo próprio produtor e por atravessadores. Como também há os produtos que são comprados na Central de Abastecimento S.A. do Rio Grande do Norte (Ceasa-RN) e são vendidos na feira livre, como apontado nas entrevistas com os feirantes e na entrevista com o representante da Prefeitura:

É onde os produtores comercializam seus produtos, tanto os produtores como as pessoas que são feirantes, eles compram estes produtos uma boa parte aqui do município, eles absorvem esta produção para poder comercializar e outros pegam na CEASA, mas uma boa parte destes produtos sai daqui de Ceará-Mirim. Existem os que produzem e comercializam direto ao consumidor, existem outras que só vendem, ou através do atravessador ou através do próprio feirante. (...) E a feira tem importância econômica, porque ela faz com que estes produtos cheguem e gerem renda para quem produz e quem comercializa e é uma oportunidade das pessoas conseguirem um produto de boa qualidade e com preço menor do que 
nos mercados. (Entrevista realizada no dia 11 de Abril de 2016 com o secretário de Agricultura).

Os trabalhos de Dantas (2007) e Queiroz (2014; 2015) mostram a importância da Ceasa-RN não só para o abastecimento dos supermercados com frutas, legumes e verduras, como também, demonstra a importância desse objeto geográfico para as feiras livres da Região Metropolitana de Natal. Esses trabalhos também indicam que as frutas, legumes e verduras originam-se das regiões Sul e Sudeste do Brasil, como também dos estados do Ceará, Bahia, Sergipe, Pernambuco e Paraíba na região Nordeste, e principalmente dos municípios de Açu, Baraúna e Touros no estado do Rio Grande do Norte. Nesse contexto, a escala de abrangência da feira livre de Ceará-Mirim é simultaneamente nacional, regional e local.

Seis dos dez feirantes entrevistados utilizam como meio de transporte para levar os produtos à feira livre de Ceará-Mirim o caminhão fretado. Os outros quatro utilizam o veículo próprio, geralmente caminhonetes e pick-ups, como podemos observar no Quadro 02.

Quadro 02- Feirantes - meio transporte de mercadorias utilizado.

\begin{tabular}{|c|c|c|}
\hline Feirantes & \multicolumn{2}{|c|}{ Meios de transporte } \\
\hline & Caminhão fretado & Carro Próprio \\
\hline F01 & & X \\
\hline F02 & X & \\
\hline F03 & X & \\
\hline F04 & X & \\
\hline F05 & X & \\
\hline F06 & X & X \\
\hline F07 & & \\
\hline F08 & & $X$ \\
\hline F09 & $X$ & \\
\hline F10 & & \\
\hline
\end{tabular}

Fonte: Pesquisa de campo, Agosto, 2015.

O transporte de mercadorias no interior da feira livre de Ceará-Mirim é feito por meio de carro-de-mão, como observamos na Foto 08. Esse transporte no interior da feira serve para ajudar os feirantes e também os consumidores, na medida em que o carro-de-mão é utilizado como se fosse um carrinho de compras de supermercado. Porém, a condução do transporte não é feita pelo consumidor como é observado nos supermercados. Na feira livre, o carro-de-mão é transportado por crianças e adolescentes trabalhadores, que utilizam a renda ou os trocados ganhados para ajudar a família. Tal fato não só é observado na feira livre de Ceará-Mirim, como também nas feiras livres de Natal (QUEIROZ, 2011; QUEIROZ \& AZEVEDO, 2012; 2013). 


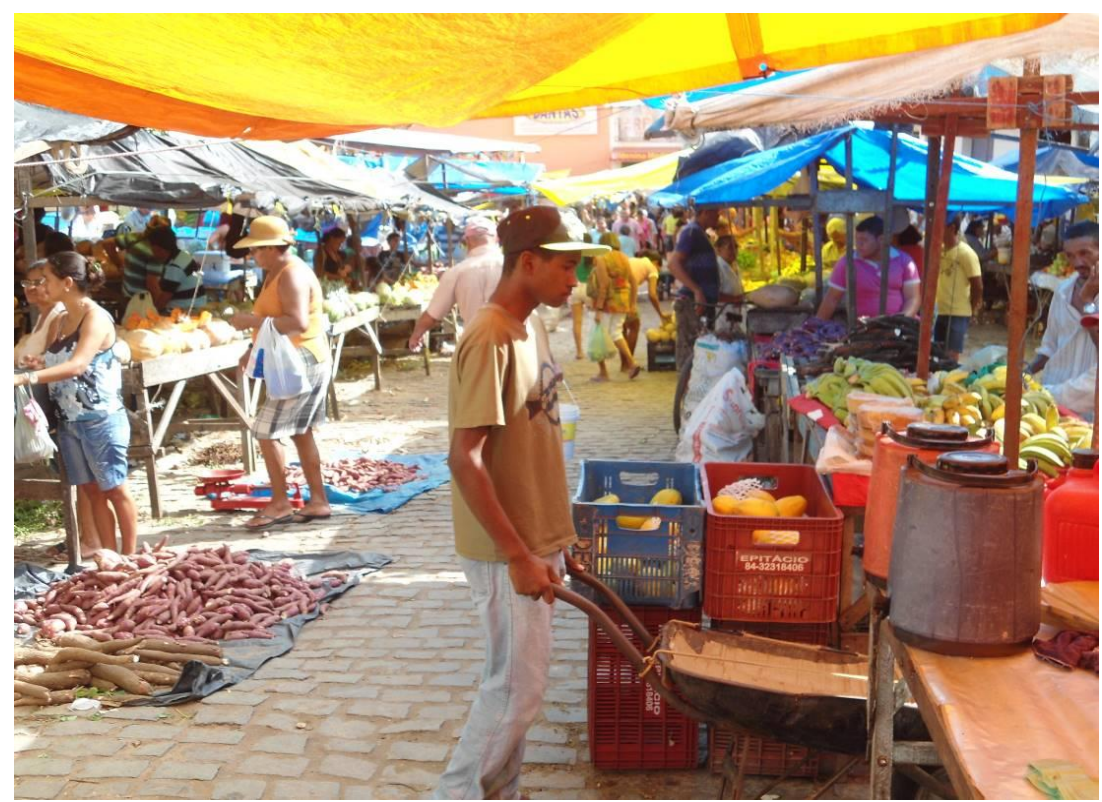

Foto 08 - Meio de transporte bastante utilizado na feira livre.

Foto: Renata de Sousa Maranhão, Agosto 2015.

Essa rede fluxos de pessoas e mercadorias na feira livre de Ceará-Mirim torna-se mais complexa quando, entre as pessoas acrescentamos os consumidores. Seis dos dez consumidores entrevistados residem na zona urbana de Ceará-Mirim. Três dos dez entrevistados residem na zona rural, nas comunidades de Lagoa do Cosme, Boa Vista e Assentamento São José do Pedregulho. O outro consumidor reside em Extremoz, município vizinho, como podemos observar no Quadro 03.

Quadro 03 - Consumidores: Município em que reside- zona urbana/zona rural de Ceará-Mirim/RN

\begin{tabular}{|c|c|c|c|}
\hline Consumidores & Ceará-Mirim/ZU & Ceará-Mirim/ZR & Outro município \\
\hline 01 & -------------- & Lagoa do Cosme & ------------ \\
\hline 02 & Ceará-Mirim & ------------ & |----------- \\
\hline 03 & Ceará-Mirim & ------------ & ------------ \\
\hline 04 & ------------ & Boa Vista & ------------ \\
\hline 05 & Ceará-Mirim & ------------ & ------------ \\
\hline 06 & Ceará-Mirim & ------------ & ------------ \\
\hline 07 & 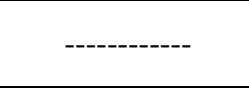 & $\begin{array}{l}\text { Assentamento São } \\
\text { José do Pedregulho }\end{array}$ & -- \\
\hline 08 & ------------ & ------------ & Extremoz \\
\hline 09 & Ceará-Mirim & ------------ & ------------- \\
\hline 10 & Ceará-Mirim & ------------ & ------------- \\
\hline
\end{tabular}

Fonte: Pesquisa de campo, Agosto, 2015.

As pessoas que compram e consomem produtos na feira, o fazem semanalmente, por achar os preços mais em conta do que os encontrados nos objetos geográficos do circuito superior como os supermercados. Além disso, muitos consumidores apresentaram a maior diversidade e os alimentos mais frescos como fator positivo e atrativo da feira livre.

Todos os consumidores entrevistados, conforme Quadro 04, comprar frutas na feira livre. Oito dos dez entrevistados compram legumes e verduras. Seis deles adquirem carnes e roupas na feira livre. Por fim, apenas dois dos consumidores entrevistados buscam alimentos não perecíveis na feira livre. Na feira livre de Ceará-Mirim não só há trocas (venda e compra de mercadorias), mas também há o consumo, por exemplo, de caldo de cana, de pastéis, de tapiocas, de sucos, elementos da culinária regional do Nordeste e do Rio Grande do Norte que são produzidos ali 
mesmo na feira livre. Assim, a feira livre não é só um local de comércio, mas também, um local de produção, circulação e consumo.

Quadro 04 - Produtos consumidos na feira livre

\begin{tabular}{|c|c|c|c|c|c|}
\hline $\begin{array}{c}\text { Consumidores / } \\
\text { Compradores }\end{array}$ & Frutas & $\begin{array}{c}\text { Legumes/ } \\
\text { Verduras }\end{array}$ & Carnes & Roupas & $\begin{array}{c}\text { Alimentos } \\
\text { não perecíveis }\end{array}$ \\
\hline C 01 & $\mathrm{X}$ & & & & \\
\hline C02 & $\mathrm{X}$ & $\mathrm{X}$ & $\mathrm{X}$ & $\mathrm{X}$ & \\
\hline C 03 & $\mathrm{X}$ & $\mathrm{X}$ & & & \\
\hline C 04 & $\mathrm{X}$ & $\mathrm{X}$ & $\mathrm{X}$ & $\mathrm{X}$ & $\mathrm{X}$ \\
\hline C05 & $\mathrm{X}$ & $\mathrm{X}$ & $\mathrm{X}$ & & \\
\hline C 06 & $\mathrm{X}$ & $\mathrm{X}$ & & $\mathrm{X}$ & \\
\hline C 07 & $\mathrm{X}$ & $\mathrm{X}$ & $\mathrm{X}$ & $\mathrm{X}$ & \\
\hline C 08 & $\mathrm{X}$ & $\mathrm{X}$ & $\mathrm{X}$ & $\mathrm{X}$ & $\mathrm{X}$ \\
\hline C 09 & $\mathrm{X}$ & $\mathrm{X}$ & $\mathrm{X}$ & & \\
\hline C 10 & $\mathrm{X}$ & & & $\mathrm{X}$ & \\
\hline
\end{tabular}

Fonte: Pesquisa de campo, Agosto, 2015.

A feira livre do Mercado central em Ceará-Mirim é reconhecida por sua importância histórica e cultural, como também, pela sua importância econômica para o município. Porém esse objeto geográfico é território de conflitos entre os feirantes e os representantes do poder público. Esses conflitos surgem quando se busca melhorias de salubridade, segurança e organização para a sua estrutura. Essas melhorias devem ser uma luta constante dos feirantes e da sociedade como um todo para que a feira livre permaneça e se fortaleça frente às figuras mais modernas do circuito superior.

\section{CONSIDERAÇÕES FINAIS}

Constatamos que a dialética entre o circuito superior e o circuito inferior da economia urbana, no atual período técnico-científico-informacional, ocorre nos lugares. As feiras livres, como a de Ceará-Mirim, apesar de serem predominantemente constituídas por elementos e características do circuito inferior, há alguns elementos do circuito superior que circulam nas feiras. Portanto, as feiras livres são lugares onde ocorre a dialética entre o circuito superior e o circuito inferior, entre as relações de verticalidade e horizontalidade, entre as solidariedades organizacionais e orgânicas, entre as racionalidades e contra racionalidades. As feiras livres são lugares que participam de diversas redes em diferentes escalas, desde a local a nacional, quiçá global, territórios de conflitos, elementos de uma cultural regional.

A pesquisa nos mostrou que $54 \%$ do Produto Interno Bruto (PIB) do município de CearáMirim origina-se dos comércios e serviços, e que $90 \%$ dos estabelecimentos formais e $99 \%$ dos estabelecimentos informais pertencem a esse setor econômico. A feira livre do Mercado Central de Ceará-Mirim é um desses elementos de comércios e serviços que dinamiza a economia do município. Porém, a feira livre de Ceará-Mirim também tem uma importância histórica e cultural, na medida em que é realizada desde o século XIX. Atualmente é realizada todos os sábados dando uma maior dinâmica ao comércio local.

A feira livre do Mercado Central de Ceará-Mirim tem diversas expressões do circuito inferior da economia urbana, tais como: o trabalho intensivo, o capital reduzido, a organização tradicional, o volumoso número de empregos gerados, o trabalho não-assalariado, os pequenos 
estoques de mercadorias, os preços submetidos à discussão entre comprador e vendedor, a margem de lucro reduzida (fazendo com que alguns feirantes busquem outra fonte de renda familiar), relações diretas e personalizadas entre feirantes e consumidores, custos fixos desprezíveis, e com ajuda governamental restrita à limpeza da feira após a sua finalização.

Porém, a feira livre de Ceará-Mirim também tem algumas características, mesmo que incipientes, do circuito superior da economia urbana, por exemplo, algumas mercadorias de grandes marcas internacionais e nacionais e alguns produtos industrializados que são vendidos na feira. Tal fato mostra o uso dos elementos do circuito inferior, como as feiras livres, pelo circuito superior para a capitalização e obtenção de mais lucro.

Quanto aos fluxos de pessoas, a feira livre tem feirantes e consumidores, principalmente, residentes no próprio município de Ceará-Mirim. Porém, há uma atração de feirantes e consumidores dos municípios circunvizinhos, criando-se uma região funcional de fluxos para a feira livre. Além disso, quando destacamos a origem das mercadorias, esses fluxos para a feira tornamse nacionais e regionais, aumentado sua escala de abrangência.

Por fim, constatamos diversos conflitos entre feirantes e o Estado, mostrando que a feira livre de Ceará-Mirim também é um território de lutas. Os feirantes, assim como os consumidores, reivindicam melhores condições ambientais na feira livre, tais como: salubridade, segurança, organização e padronização. A Prefeitura Municipal se propõe a ajudar nessa organização, porém, alegando falta de recursos, só dispõe de limpeza após a realização da feira livre, faltando pontos de água, pontos de eletricidade, banheiros químicos, seguranças, coletores de lixo e a tão sonhada padronização. Contraditoriamente, os feirantes não se organizam politicamente em associações e cooperativas que poderiam ajudá-los nas reivindicações e na luta pelas melhorias das condições de trabalho.

Esperamos que nosso trabalho possa ser lido pelas autoridades responsáveis, e possa ser uma contribuição para a luta dos trabalhadores, em especial dos feirantes, por melhores condições de trabalho. Por fim, enfatizamos a necessidade de fortalecer a feira livre do Mercado Central de Ceará-Mirim (e de todos os elementos do circuito inferior da economia urbana diante da expansão do circuito superior) com políticas públicas de padronização das bancas, organização setorial, instalações sanitárias, pontos de água e energia elétrica, para assim manter vivo esse elemento geográfico que tem uma importância histórica, cultural e econômica para Ceará-Mirim.

\section{REFERÊNCIAS}

1. CORRÊA, Roberto Lobato. A rede de localidades centrais nos países subdesenvolvidos. Revista Brasileira de Geografia. Rio de Janeiro: IBGE, 50(1):61-83, Jan./Mar. 1988.

2. DANTAS, Geovany Pachelly. Feira de Macaíba/RN: um estudo das modificações da dinâmica socioespacial (1960/2006). Dissertação (Mestrado em Geografia). Natal: UFRN, 2007.

3. IBGE - Instituto Brasileiro de Geografia e Estatística. IBGE - Cidades - Rio Grande do Norte Ceará-Mirim. Acesso em: 2016. Disponível em: http://cidades.ibge.gov.br/xtras/perfil.php? codmun $=240260$

4. MASCARENHAS, Gilmar. O lugar da feira livres na grande cidade capitalista: Rio de Janeiro, 1964-1989. Revista Brasileira de Geografia, Rio de Janeiro, v.54, n.1, p. 95-120, jan./mar. 1992. 
5. MARANHÃO, Renata de Sousa. Avaliação dos riscos higiênico-sanitários da feira livre do Mercado Central no município de Ceará- Mirim/RN. Monografia (Graduação em Geografia). Natal: UFRN, 2012.

6. MELO, Bartolomeu Correia de. Estória de oitiva da feira do Ceará-Mirim, 08 de abril de 2011. Disponível em: http://gibsonmachadocm.blogspot.com.br/2011/04/estoria-de-oitiva-dafeira-do-ceara.html

7. QUEIROZ, Thiago Augusto Nogueira de. As feiras livres de Natal-RN: um estudo a partir da teoria dos circuitos da economia urbana. Monografia (Graduação em Geografia). Natal: UFRN, 2011.

8.

A Ceasa-RN e os circuitos da economia urbana: a circulação de hortifrutigranjeiros em Natal-RN. Dissertação (Mestrado em Geografia). Natal: UFRN, 2014.

9. As centrais de abastecimento alimentar: agentes mistos dos circuitos da economia urbana. Sociedade e território, Natal, v.27, n.1, p.157-177, jan./jun. 2015.

10. ; AZEVEDO, Francisco Fransualdo de. Circuitos da economia urbana: arranjos espaciais e dinâmica das feiras livres em Natal-RN. Sociedade e território, Natal, v.24, n.1, p.115-133, jan./jun. 2012.

11. ; AZEVEDO, Francisco Fransualdo de. As feiras livres e suas (contra)racionalidades: periodização e tendências a partir de Natal-RN-Brasil. Biblio 3W. Revista Bibliográfica de Geografía y Ciencias Sociales, Barcelona, Vol. XVIII, no 1009, 15 de enero de 2013.

12. SANTOS, José Erimar dos. Feiras livres e circuitos da economia urbana: um estudo da Feira da Pedra, em São Bento (PB). Dissertação (Mestrado em Geografia). Natal: UFRN, 2012.

13. SANTOS, Milton. O espaço dividido. Rio de Janeiro: Francisco Alves, 1979.

14. A natureza do espaço. São Paulo: Hucitec, 1996.

15. Por uma outra globalização. Rio de Janeiro: Record, 2000.

16. SEBRAE-RN - Serviço Brasileiro de Apoio às Micro e Pequenas Empresas do Rio Grande do Norte. Perfil Empresarial - Ceará-Mirim. Acesso em: 2016. Disponível em: http://rn.sebrae. com.br/app/webroot/estudos-e-pesquisas/conjuntura-do-rn/

17. SOUZA, Marcelo Lopes de. Os conceitos fundamentais da pesquisa socioespacial. Rio de Janeiro: Bertrand Brasil, 2013. 